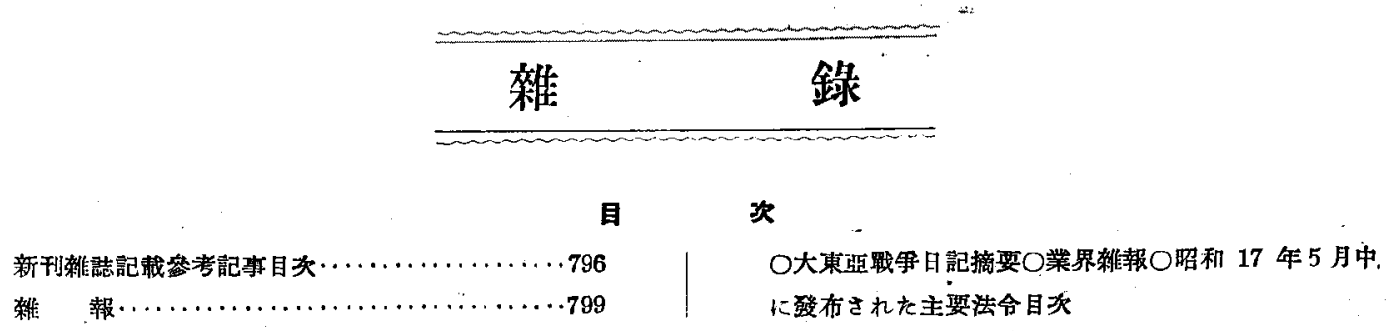

新刊雜誌記载參考記事目次

\section{i. 慗鐵原料}

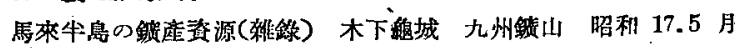
216

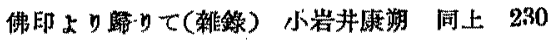

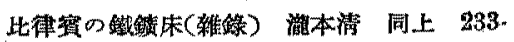

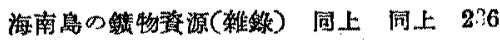

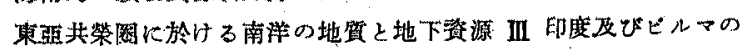

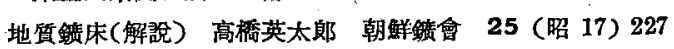

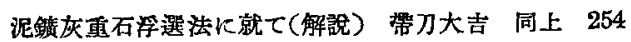

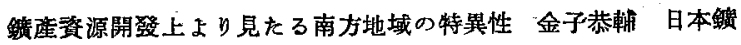
業會 58 (昭 17) 193

比岛の金・銅・クロム・マンガン (1. 金；2. 銅・クロム・マン

ガン) 周部楠男 同上 200,295

馬來の较 石川英助 同上 209

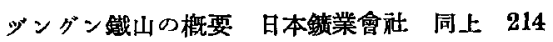

ピルマ及び隶の銔業 印果善二同上 224

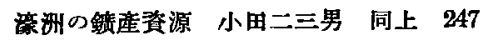

ニュージーランド 小林儀一郎 同上 256

大東亞銈物值源の展望 山根新次 同上 277

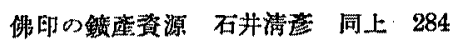

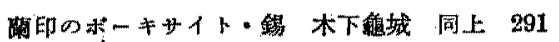

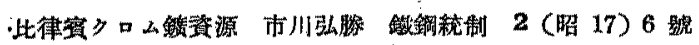

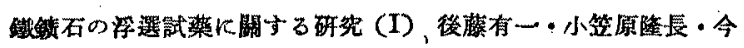

泉又满洲结金學會 4 (昭 17) 33 號

硫酸涬成分の顯微鏡的䚋察 森棟隆弘 同上同上

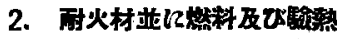

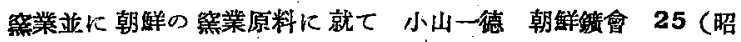
17) 215

粗昰炭有教利用法㮽要 麻生幹夫 日本機栰學會 45 (昭 17) 352

粗昰炭の有效利用 外川正見 同上 356

頪甸吅油田大村一藏 日本的業會 58 (昭 17) 300

スマトラの油田 同上 同上 304

ジャベの油田 千谷好之助，同上 309

ボルネオの油田 大村一藏 同上 317

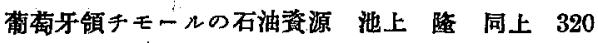

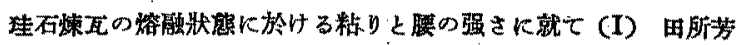

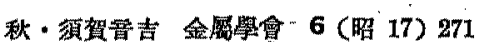

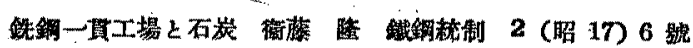

製銅用热順炭の配給飞就て 鈴木長晩 同上同上

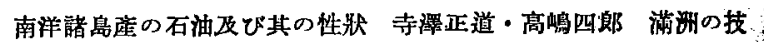
衡 19 (昭 17) 135

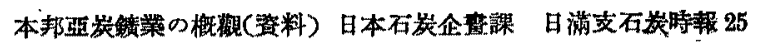

㩆 (昭 17 ) 419

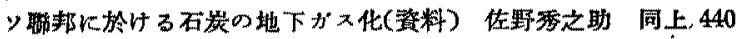

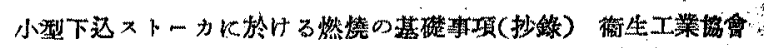

16 (昭 17) 481

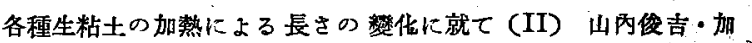

藤左㼄 大日本等業坫會 50 (昭 17) 259

見掛比重の禁化に依るマグネシア犋耐火物の蒸氮抵抗試驗 由中

泰夫・高木件篦 同上 262

フォルステライト耐火物の製造に關する研究(II) 池田嘉夫同

上 266

各程烓石の附火度比較测定結果 田所芳秋・須賀宫吉 间上 298

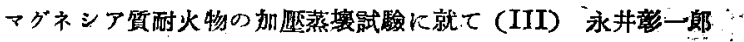

同上 269

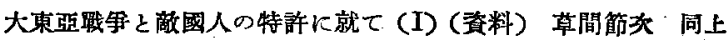
288

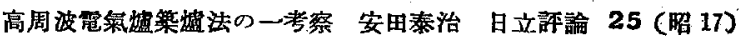
280

\section{3、銖鐵及び合金臷の賠造}

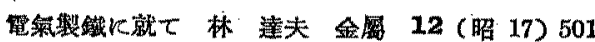

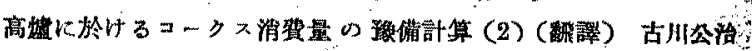

4 (昭 17) 33 暍

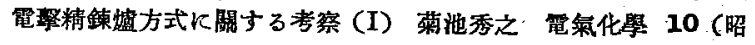

17) 169

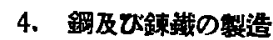

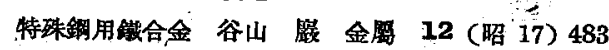

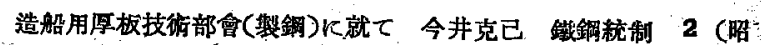

17) 6 號

5. 臷及ひ鉱の等造

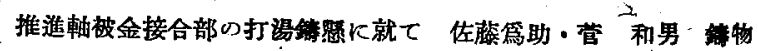

14 (昭 17) 121

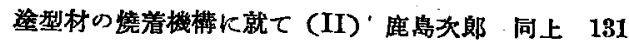

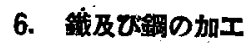

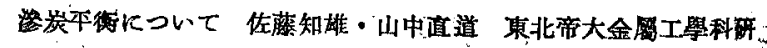
先啹告 23 (昭 17 ) 658

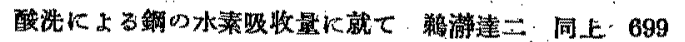

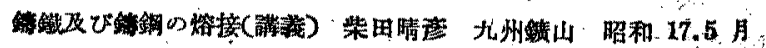


197

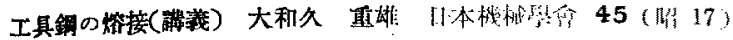
831

蛙入昌本-4- 高做孝夫臎 金屬 12 (昭 17) 493

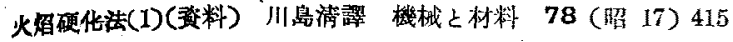

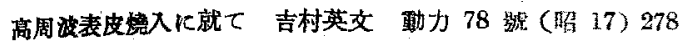

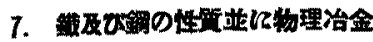

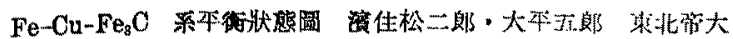
金最工學科研究報告，13（昭 17) 24

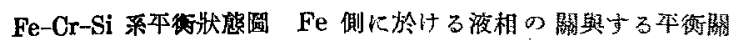

保 矢島惟炏郎 同上 455

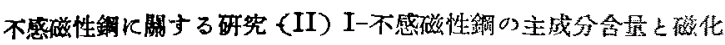

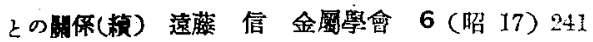

再桔晶の活性化エネルギーと自己控散の活性化ェネルギーとの關

㛊に就て 橋口陵吉 同上 282

切缺に依る㦄力心集中に就て 故小野正敏 機械學留 45 (昭 17) 406

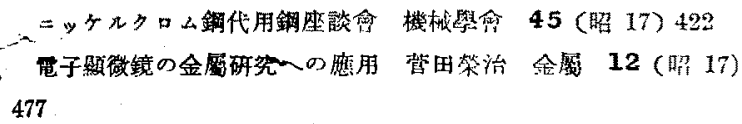

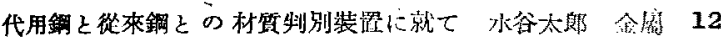
(昭 17) 511 ・

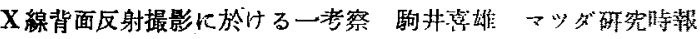
17 (昭 17) 243

超高質合金、西垣 武 機械と材料 78 (昭 17) 388

\section{8. 非鐵金属及びの合金}

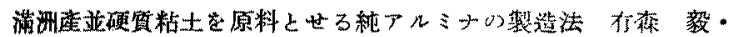
小西幸雄 アルミニウム 2 (昭 17) A65

カソードカーボンに就て 永井雅夫 同上 179

アルミナ製造諸法の數量的檢討 鈴木 䇥 同上 A79

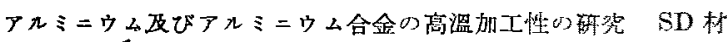

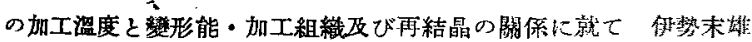
问上 $\mathrm{A} 88$

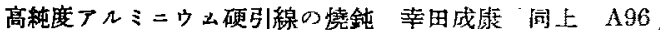

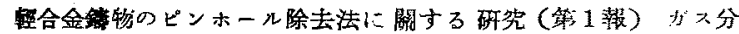

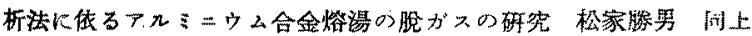
A99

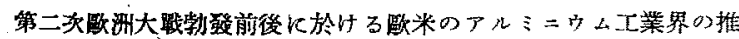
移と䔮勢(講演) 嵪橋本校 同上 A113

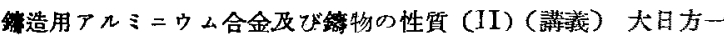
司一同上 A119

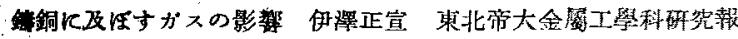
告 13 (昭 17) 512

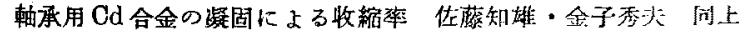
76

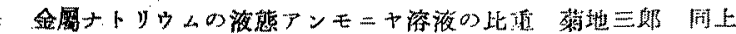
568

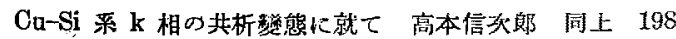

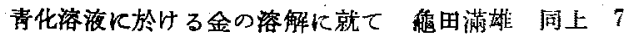

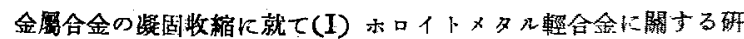

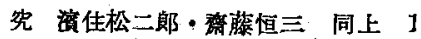

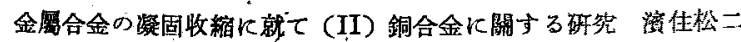

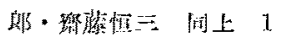

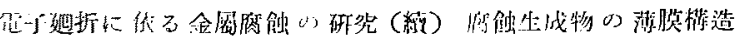

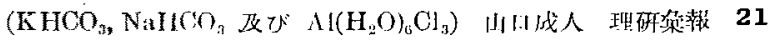
(1173 17) 399

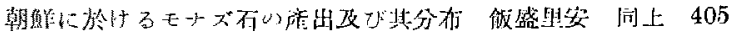

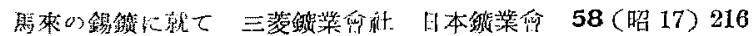

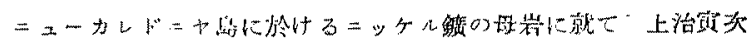

这

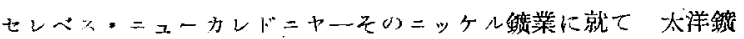

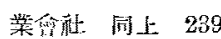

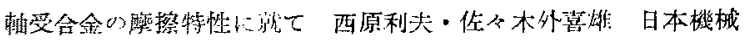
學畣 45 (昭 17) 300

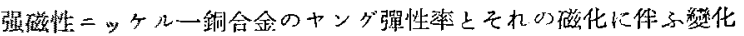

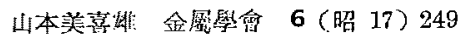

アルミニぬ仍びギュラルミンの高䀀加工と再結晶 大日方一

司・则 策—同上 258

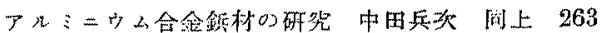

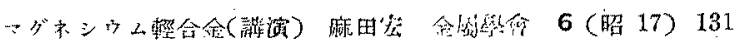

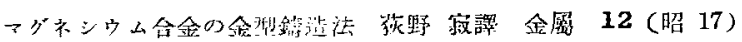
507

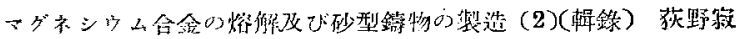

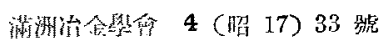

ニッタ儿(輯錄) 三奵庄入 同上同上

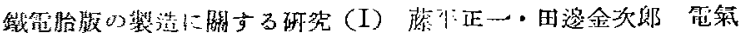
化礐 10 (昭 17) 180

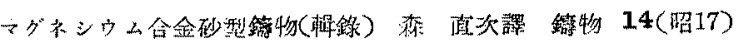

137

An Investigation of Running Quality of Magnesium and Its Aloys. Sirō Morita 京大工紀 11. (昭 17) 1 號

9. 化學分析

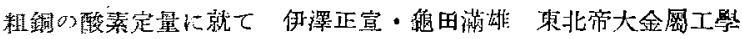
科研究㘧整 13 (昭 17) 400

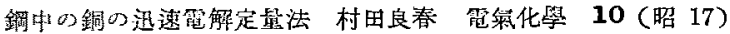
173

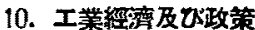

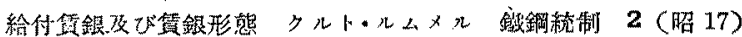
6 政

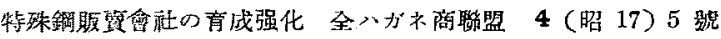

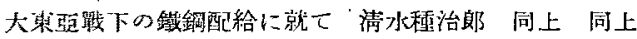
企業整锌会の施行 商工省 同上同上

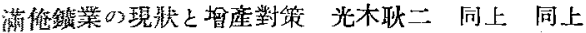

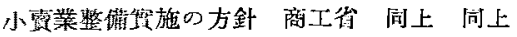

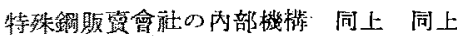

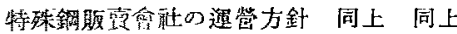

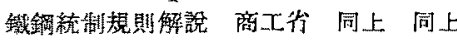

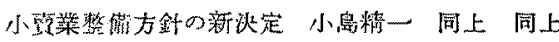

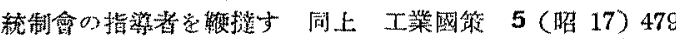
11. 藮

㯰獨雅感(請演) 大谷文太郎 アルミニウム 2(昭 17) A 103

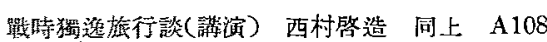

ミルト・コンベヤのベルトの張力について 小松仁美男 エンギ $=+1$ ソダ 30 (昭 17) 271 


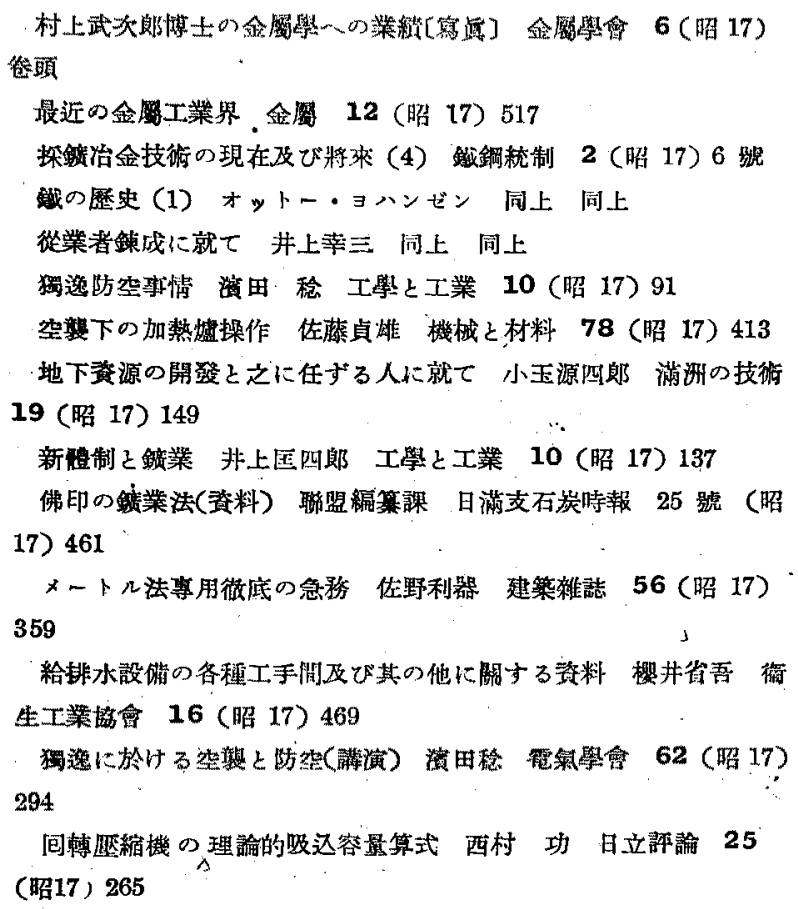

Zusammenwirken von Wasserstoff und Spannungen bei Entstehung von Flockenrissen. Von E. Houdremont \& Schrader. (Stahl \& Eis. 1941, 61 Jg., H. 27.)

Anordnung und Betrieb von Pfannensinteranlage Bauart GFHAIB. Von Rodolf Hahn. (-do H. 27.)

- Wirtschaftlichkeit der neuzeitlichen Gesenkoberdampfhammers. Von Knorr. (do. H. 28.)

Gefaser der Flockenrissbildung durch Wasserstoffaufnahme bei Stahlverarbeitung. Von E. Houdremont \& Sehrader. (do. H. 28.)

Zweckmässigste \& Bau von Lichtbogenofenstahlwerken. Von Heinrich Müller. (do. H. 29.)

Vergasung westdeutscher Steinkohlen. Von Erwin Russ. (do. H. 29, H. 30)

.Uebermikroskopie. Von Bodo von Borries. (do. H. 31.)

Umbau eines Edelstahlwalzwerkes. Von Alogs Fischnich. (do. H. 32.)

Wasserstoff als Legitrungselement bei Stahl und Gusseisen. Von Houdremont und Heller. (do. H. 32.)

Anordnung und Betrieb Greenawaltsinteranlage auf Julienhütte. Von Carl. Schrupp. (do. H: 33)

Elektronenmikroskop, Uebermikroskop, Metallfor schung. Von Walter Henneberg. (do. H. 33.)

Mit Silizium und Aluminium beruhigter Thamasstahl fuir Schiffsnieten. Von Hubert Auţraann, (do. H. 35.)
Einflussgrössen bel Nalurkorrosionversuchen an unlegierten und schwachlegierten Stählen, Von Mewes Daeves. (do.H.86)

Forderungen der Wehrmacht an Erziehung und Bildung: swesen. Von Fries ner. (do. H. 37.)

Heutige Stand hitzebeständiger Walz-und Schniedes tähle. Von Riedrich. (do. H. 37.)

Stand und Entwicklung der Hochofengasreinigung in letzten zehn Jahren (1). Von Guthmann. (do. H. 38.)

Featigkeitseigenschaften von Chrommanganmolydän =Vergiitungsstählen. Von Cornelius und Krainer. (do. H. 38.)

Wärmeïbergang und Wärmeverlust bei Schmieden und Pressen. Von Lueg und Pomp. (do. H. 39.)

Wissenschaftliche und technische Grundlagen der Pulvermetallurgie und Anwentungsbereich. Von Dawihl. (do. H, 40.)

S Entwicklung der Herdfrischverfahren in Witkowitz. Von Rotter. (do. H. 41, H. 42)

Buitrag zar Manganmetallurgie. Von Volkert. (do, H. 41.)

Neue elektrische Gichtgasreinigung des Hochofenwerkes Oberscheld Buderussche Eisenwerke. Von Eichler. (do. H. 42.)

Formgebung und Werkstoffausnutzung. Von Dring Lebr: (do. H. 43.)

Messungen über Mass der Unterkïhlung bei Kokillenguss. Von Siegel. (do. H. 44.)

Einfluss der Seigerung und Verschmiedung auf Festigkeitseigenschaften grosser Schmiedestücke aus Stahl. Von Coupette. (do. H. 45.)

Verschleiss metallischer Werkstoffe. Von Eichinger. (do. H. 45.)

Therie der Windfrischverfahren. Von Kootz. (do, H. 47.)

. Verwendungsmöglichkeiten von nich(rostenden und hitzbeständigen Stählen mit Stickstoffzusatz. Von Rapatz. (do, $\mathrm{H}$, 48.)

Bau und Betrieb zweistufiger elektrischer Hochofengast reinigangganlagen, Vori Rabe. (do..H. 48.)

Neues Panzerplattenwalzwerk. Von Münker. (do. H. 49.)

Fortschritte an Herstellung von Sintermagneten aus Eisen $=$ nickelaluminium-Legierung. Von Hotop. (do. H. 49.) - :

Leichtmetalle und Stahl als Werkstoffe. Von Schula, (do. H. 50.)

Suerstoffhobeln von Stahl. Von Wolff. (do. H. 50.).

Bergbauliche Möglichkeiten Afrikas für Eisenhüttenindus: trie, Wichitige :Rohstoffe. Von Prof. Schumacher. (do, H. 51.) Frostschutzmassnahmen in Hiittenbetrieben. Von Guth mann. (do. H. 5l.)

Grobkornhärterisse in Werkzeugen aus Schnellarbeitstabl und Vermeidung. Von Pattermann. (do. H. 52.)

Auffederung des Ziehgutes nach Durchgang durch Ziehwerkzeug. Von Lueg und Pomp. (do. H. 52.) 